\title{
Automotive Parts Purchasing Using the Fuzzy MOMIP Model of Reliability Objective with Uncertain Weights
}

\author{
Zeshui XU ${ }^{1 *}$, Jia jia CHEN ${ }^{1,2}$, Jianmei YE ${ }^{1,2}$, Jianchuan ZHANG \\ ${ }^{1}$ Business School, Sichuan University, No. 24 South Section 1 Yihuan Road, Chengdu, 610064, China \\ xuzeshui@263.net(*Corresponding author),jiajia_818@126.com \\ ${ }^{2}$ School of Economics and Management, Chongqing University of Posts and Telecommunications, \\ No. 2 Chongwen Road, Nan'an District, Chongqing, 400065, China \\ yejianmei2423@163.com \\ ${ }^{3}$ SOKON Industry Group Stock Corporation Ltd, No. 61-1 Jinqiao Road, Shapingba District, \\ Chongqing, 400033, China \\ jianchuan@126.com
}

\begin{abstract}
This paper develops an effective order allocation method considering a reliability objective, fuzzy information provided by candidate suppliers and uncertain objective weights, and uses it to provide automotive parts procurement solutions. A fuzzy multi-objective mixed integer programming (MOMIP) model with uncertain objective weights is formulated to minimize total cost, the unqualified automotive parts and to maximize supply reliability, obtained by a synthetical evaluation of five criteria including financial status stability, technique of product reliability, quality reliability, service and environment sustainability. An extended interactive algorithm is developed to solve the model. By applying it in a case of sensor parts purchasing under an operational context of industry 4.0, the result shows that the reliability objective is effective in supplier selection and order allocations; and that the interactive algorithm only requiring the preference order on the objective weights from decision makers is also effective.
\end{abstract}

Keywords: Fuzzy MOMIP model, Reliability objective, Uncertain objective weights, Extended interactive algorithm, Industry 4.0.

\section{Introduction}

With the development of industry 4.0 , multiobjective procurement plays an important role in the supply chain management, especially in supplier selection and order allocation (Asdecker \& Felch, 2018). Procurement decisions for supplier selection and order allocation involve the optimization for multiple objectives which may conflict with each other (Xu, 2002, 2007; Gou et al., 2017; Yaghin \& Darvishi, 2020; Sillanp et al., 2021). Considering the confliction of the optimization objectives, including quality, cost, delivery, service, etc., the corresponding multiobjective optimization procurement models for manufacture industry were proposed (Zhou et al., 2019). In the automotive industry, an important goal of multi-objective procurement is to meet the needs of purchasers with high service level, high quality of products and lower total cost. To further improve the purchaser satisfaction, more factors are considered under the background of industry 4.0 , such as the uncertainty from the complex environment, the discount policy and the reputation of suppliers, etc., (Han et al., 2018; 2019; Caiado et al., 2020). The purchasers not only care about quality and cost, but also consider the reliability from the trust relationship between purchasers and suppliers which involves the suppliers' reliable performance of financial status, ability for technical innovation and production capacity, advancement products, service level, etc.

Reliability reflects purchaser satisfaction for products or trust in suppliers. Its features contain not only the sustainability of service, quality and financial stability (Kellner \& Utz, 2019; Sarkar et al., 2020), but also cover the comprehensive performance integrated by the technique reliability, stable production and environment sustainability (Zhou et al., 2020). To improve the reputation of suppliers, reliability has been treated as one of the procurement objectives to be optimized in supply chain management (Tirkolaee et al., 2020; Dai et al., 2021). The existing reliability objective focuses on maximizing the average quantities of the products delivered by the suppliers to the purchasers. However, the existing optimization methods for the reliability optimization are unsuitable for the emerging industry procurement because the reliability in the context of industry 4.0 involves multiple evaluation criteria that refer to more than average quantities of the products. In industry 4.0 environment, the reliability should be a comprehensive objective produced from supplier reliability performance of multiple evaluation criteria including suppliers' financial and technology stability, production and 
environment sustainability as well as service and quality reliability.

In the industry 4.0 environment, due to the heterogeneity of intelligence technology for the equipment, the dynamic of market and the limitation of decision makers, the provided procurement information is always uncertain, which presents a significant challenge for the supply chain management. Thus, uncertain procurement information has been introduced in the multi-objective procurement models to improve the application in fuzzy environment scenarios (Seyed Haeri \& Rezaei, 2019; Pamucar et al., 2020). There are several uncertain factors, such as fuzzy demand, imprecise defect rate and inaccurate production capacity, etc. These uncertainties are often expressed by imprecise terms such as "pessimistic", "most likely" and "optimistic", and these fuzzy elements are always converted into accurate values in computational procedures (Chatterjee \& Kar, 2018). Although fuzzy objective weights were expressed in triangular fuzzy values in Yu et al. (2012), fuzzy objective weights are not limited to the expressions of "pessimistic", "most likely" and "optimistic" for decision makers, which are usually expressed as a dynamic range in real cases.

This paper develops a fuzzy multi-objective mixed integer programming (MOMIP) model which optimizes total cost, quality and comprehensive reliability to find the optimal order allocations for suppliers. In this model, a reliability function introducing a reliability performance parameter is built which can be determined according to synthetical evaluation criteria consisting of reliable financial status, sustainable technique and production, reliable quality, service and product environment. In addition, fuzzy factors, quantity discount and budget limitation are also considered in this model and these elements enable the model to be applied to more complex environment. An interactive algorithm is developed for solving the proposed model, in which procedures for generating possible objective weights are introduced to enable the feasible of the approach under the uncertain objective weights. The model is applied to a case of sensor parts procurement of SOKON Industry Corporation Ltd. The contributions of this paper are as follows:
1. This paper introduces a comprehensive reliability function to extend the reliability objective integrated with financial status, technique of product, quality stability, service and environment sustainability, which better meets the operational requirements for the industry environment.

2. By introducing a procedure of an interactive weight determination with computational experiments assuming uncertain prior weights, this paper yields a set of objective weight that is better implemented by decision makers. Thus, a preference order of the objective weights will suffice in finding an optimal solution.

3. By analyzing the solution's frequency under uncertain objective weight, this paper provides an effective approach of objective values prediction (i.e., total cost, quality and reliability), and further may help decision makers to adjust plans afterwards.

The paper is organized as follows: Section 2 reviews the related literature. Section 3 elaborates the methodology to solve supplier selection and order allocation containing the establishment of the fuzzy MOMIP model and an interactive algorithm to solve the model with uncertain objective weights. In Section 4, this model is applied in an automotive sensor parts procurement case of Chongqing SOKON Industry Group Stock Corporation Ltd in China. Subsequently, Section 5 discusses the solutions and objective values with uncertain objective weights and analyzes the overall achievement level and order allocations for different preference orders of objective weights. Finally, the conclusions are drawn in Section 6.

\section{Literature Review}

Automotive parts purchasing is a complex decision-making process which includes activities of supplier selection and order allocation (Manello \& Calabrese, 2018). For automotive parts procurement, sensor part is the core part in the industry 4.0 context which consists of "pressure sensor", "temperature sensor", "fuel sensor", "knock sensor", etc. (Setiawan et al., 2020). In the industry 4.0 environment, sensor part suppliers are required to provide more intelligent equipment, which not only collect data, but also process, store and send data (Baroudi \& Haque, 2021).

https://www.sic.ici.ro 
Since the Industry 4.0 has become a flag for a competition of industrial procurement, which not only changes technologies but also guides new commercial mode to find trusted businesses relationships (Frank et al., 2019). The activities of supplier selection and order allocations under the new trend of automotive industry have been studied during recent years, especially for the automobile parts procurement (Galankashi et al., 2016; Ghadimi et al., 2019).

Under the environment of industry 4.0, buyers and sellers always consider reputation as a crucial factor to build their relationship (Manello \& Calabrese, 2018; Salam \& Ali, 2020). As such, a few studies focus on reliable supply chain recently. Tang et al. (2014) developed an endogenous reliability model that considers supply risk mitigation strategies in a decentralized supply chain setting, where supplier's reliability was decided by the perfectyield probability and the imperfect yield rate. In another study, Poudel et al. (2016) established a reliable model that helped the governance of a bio-fuel supply chain network which minimizes the total costs and considers the maximum reliability that can be reached with availability. Based on mixed-integer programming (MIP), Mohammadi (2020) presented a reliable model in which the procurement lot-sizing with discount and multiple transportation modes are considered. Since sustainability theory is asSoCiated with reliability in the supply chain management, scholars investigated the two theories simultaneously in supply chain management up-to-date. A sustainable and reliable hydrogen supply chain network was developed by Fazli-Khalaf et al. (2020), which maximizes the reliability of the network against disruptions through the concurrent establishment of reliable and unreliable hydrogen manufacturing facilities. A recent study by Tirkolaee et al. (2020) proposed a novel hybrid method to solve sustainable-reliable supplier selection which minimizes total cost of the chain and maximize the weighted value of products and the reliability of the supply chain. The authors maximized reliability through maximizing the average quantities of the products delivered by the suppliers to the purchasers. Concluded from the above, although reliability has been regarded as an optimal objective in existing models, the existing models fail to take reliability as a comprehensive objective containing multiple dimensions of information. Therefore, this paper focuses on establishing a comprehensive reliability objective that integrates the multiple information of reliability from systematic reliability evaluation criteria for automotive parts purchasing.

Uncertain information is an important factor in establishing a model for purchasing optimization, and it has also been considered as a vital element for solving multiple objectives optimizing models (Chen \& Xu, 2015; Xu \& Wang, 2016; Gupta et al., 2019). Uncertain information for procurement includes uncertain demand, imprecise delivery time, inaccurate defect rate and uncertain objective weight, and these fuzzy information have been investigated in the models for supplier selection (Yu et al., 2012; Khalilzadeh et al., 2020). Uncertain objective weight which reflects the preference for the optimization objective has been regarded as important information in the algorithm for finding optimal solutions (Yu \& Goh, 2014; Kaviani et al., 2020). Amid et al. (2009) developed a weighted additive fuzzy multi-objective programming (MOP) model for purchasing management optimization, the authors considered three weighted additive cases with different preferences of objectives from decision makers. Based on that model, Yu et al. (2012) adopted a fuzzy multi-objective vendor selection model in which the objective weights were imprecise and expressed as triangular fuzzy numbers. After that, Krishankumar et al. (2020) established a decision framework with unknown weight information for solving green supplier selection which focused on calculating attributes' weights when the information is completely unknown. The existing literature solved only the fuzzy purchasing model with limited weight senses, although $\mathrm{Yu}$ et al. (2012) adopted triangular fuzzy numbers for uncertain objective weights in the model, but the uncertain objective weights are not limited to three possible values (i.e., "pessimistic", "most likely" and "optimistic"). Therefore, the work from the present paper is dedicated to developing an approach to get an objective weight set with all possible weight senses when the preferences 
for objectives are known but the specific objective weights values are uncertain. Here, the preference order for objectives may change with the variation of external environment.

This paper aims to fill the gap that the existing researches in the literature have not properly solved (the automotive parts purchasing problems with synthetical reliability property), and is dedicated to developing a fuzzy multiple objective mixed integer programming model to optimize three objectives containing cost, quality and synthetical reliability. This paper improves the reliability objective proposed by Tirkolaee et al. (2020) by adopting synthetical evaluation criteria for obtaining supplier reliability performance which contains financial, production technique, quality, service and product environment. For solving the fuzzy MOMIP models with uncertain weights, an extended interactive algorithm which improves the algorithm of Yu et al. (2012) and Yu \& Goh (2014) is proposed by introducing the procedures for generating possible weights of objectives to find the optimal solution.

\section{Methodology}

At the heart of the proposed methodology is a fuzzy multi-objective mixed integer prog-ramming (MOMIP) model which improves the model of Yu et al., (2012) and Kellner \& Utz (2019). This model extends the functionality of traditional reliability to the supplier selection and order allocation, and considers fuzzy factors, quantity discount policy and variable cost constraint in the model (subsection 3.1). Furthermore, an extended interactive algorithm is proposed to solve the order allocation model with uncertain weights (subsection 3.2).

\subsection{Fuzzy Multi-Objective Mixed Integer Programming Model for Order Allocation}

The proposed optimization model has three objectives: to minimize total purchasing costs, to minimize unqualified automotive parts and to maximize total reliability value. The indices, decision variables and parameters used in the model are listed in Table 1.
Table 1. Indices, decision variables and parameters used in the model

\section{Indices:}

$j=1,2, \ldots, \mathrm{m}$ Suppliers

$i=1,2, \ldots, n$ Automotive parts

\section{Decision variables:}

$y_{i j} \quad 0-1$ variable determined by whether part $i$ is supplied by supplier $j$ ( $j=1$ if supplied; $j=0$ if not supplied)

$x_{i j}$ Orders distributed to supplier $j$ for part $i$

\section{Parameters:}

$C_{j}$ All-unit quantity discount coefficient provided by supplier $j$

$K_{i j}$ Unit variable cost for part $i$ supplied by supplier $j$

$L_{i j}$ Capacity of part $i$ for supplier $j$

$A_{i j}$ Fixed cost for part $i$ from supplier $j$

$q_{i j}$ Defect rate of part $i$ provided by supplier $j$

$p_{j}$ Reliability performance for supplier $j$

$E_{j}$ Minimum order for supplier $j$

$S_{i}$ Number of selected suppliers for part $i$

$N$ Maximum value of selected suppliers given by decision makers

$B_{j}$ Financial constraints for variable cost from supplier $j$

\section{Objectives}

Total cost

$\operatorname{Min} Z_{1}(x, y) \stackrel{\sim}{=} \sum_{i=1}^{n} \sum_{j=1}^{m}\left(1-C_{j}\right) K_{i j} x_{i j}+\sum_{j=1}^{m} A_{i j} y_{i j}$

Quality

$\operatorname{Min} Z_{2}(x) \stackrel{\sim}{=} \sum_{i=1}^{n} \sum_{j=1}^{m} x_{i j} q_{i j}$

Reliability

$\operatorname{Max} Z_{3}(x) \stackrel{\sim}{=} \sum_{j=1}^{m}\left(\sum_{i=1}^{n} x_{i j} p_{j}\right)$

Fuzzy constraints :

$\sum_{j=1}^{m} x_{i j}\left(1-q_{i j}\right) \tilde{\geq} D_{i}, \forall i$

$x_{i j} \tilde{\leq} y_{i j} L_{i j}$

Exact constraints:

$\sum_{i=1}^{n} x_{i j} \geq \sum_{i=1}^{n} \mathrm{y}_{i j} E_{j}, \forall j$

$S_{i} \leq N, \forall i$

$\sum_{i=1}^{n}\left(1-C_{\mathrm{j}}\right) K_{i j} x_{i j} \leq B_{j}, \forall j$

$y_{i j} \in\{0,1\}, \forall i, j$

$x_{i j} \geq 0, \forall i, j$ 
Equation (1) minimizes the overall purchasing costs, which consist of variable and fixed costs. Variable costs are costs for per unit selling prices under all-unit quantity discount policy. Fixed costs are costs for maintaining the relationship with suppliers and they are not affected by the variation of purchasing quantity. Equation (2) minimizes the unqualified items which reflect the quality of automotive parts. Equation (3) maximizes the total comprehensive reliability performance of the suppliers selected. The reliability performance of supplier $\mathrm{j}$ ranges between 0 and 1 .

In the model, the constraint (4) requires that the quantity of qualified products purchased from selected suppliers should meet the demand; the constraint (5) restricts the allocated quantity of the part $i$ for the supplier $j$ so that it does not exceed its capacity; the constraint (6) provides the minimum order quantity if purchased from the supplier $\mathrm{j}$; the constraint (7) enforces the upper limit number of selected suppliers for part i; the constraint (8) requires that the variable cost from the supplier i should not exceed the allowed values; the constraint (9) defines the binary characteristic of the decision variables; the constraint (10) sets the purchasing quantity as a positive integer.

\subsection{Using an Extended Interactive Algorithm to Solve the Order Allocation Model}

In this section, an interactive algorithm is proposed to solve the order allocation model with uncertain weights (see Figure 1). Assume that there are objectives which consist of minimization objectives and maximization, demand constraints. Suppose that the preference order for the objectives has been given by the decision maker. The steps of the algorithm are as follows:

Step 1. Use the triangular membership functions and the centroid method to defuzzify the fuzzy capacity, fuzzy defect rate and fuzzy demand for each automotive part.

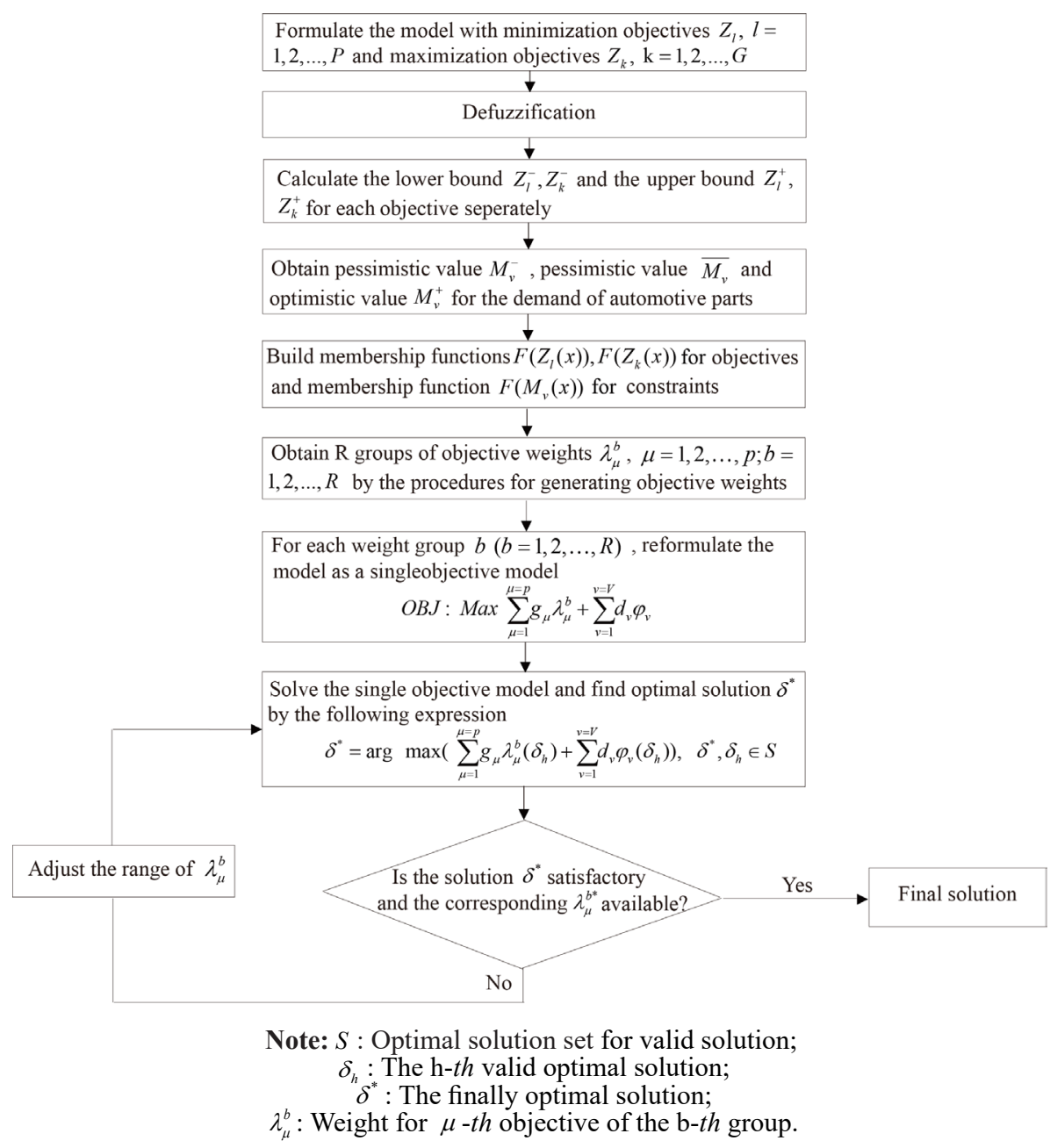

Figure 1. Logic flow of interactive algorithms for solving the model 
Step 2. For the minimization objective functions $Z_{l}(x)(l=1,2, \ldots, P)$ and the maximization objective functions $Z_{k}(x)(k=1,2, \ldots, G)$, the lower bounds $Z_{l}^{-}, Z_{k}^{-}$and the upper bounds $Z_{l}^{+}, Z_{k}^{+}$are calculated separately by using the max-min approach (Zimmermann, 1987) by the following equations:

$$
\begin{aligned}
& Z_{l}^{+}(l=1,2, \ldots, P)=\max Z_{l}(x), x \in X_{a}, Z_{l}^{-}(l=1,2, \\
& \ldots, P)=\min Z_{l}(x), x \in X_{d}, \\
& Z_{k}^{+}(k=1,2, \ldots, G)=\max Z_{k}(x), x \in X_{d}, Z_{l}^{-} \quad(l=1,2, \\
& \ldots, P)=\min Z_{l}(x), x \in X_{a} .
\end{aligned}
$$

where $Z_{l}^{-}$and $Z_{k}^{+}$are obtained by solving the model as a single objective for only one objective at each time. Here, $x \in X_{d}$ shows that solutions must satisfy constraints while $X_{a}$ is the set of all optimal solutions through solving the model as a single objective (Amid et al., 2006).

Step 3. Obtain the pessimistic values $M_{v}^{-}(v=$ $1,2, \ldots, V)$, the probable values $\bar{M}_{v}(v=1,2, \ldots$, $V)$ and the optimistic values $M_{v}^{+}(v=1,2, \ldots, V)$ from decision makers for the demand of automotive parts.

Step 4. Build membership functions for fuzzy objective functions and fuzzy demand constraints, respectively. The membership functions $F\left(Z_{l}(x)\right)(l=1,2, \ldots, P)$ for fuzzy minimization objectives, $F\left(Z_{k}(x)\right)(k=1,2, \ldots, G)$ for fuzzy maximization objectives and the membership functions $F\left(M_{v}(x)\right)(v=1,2, \ldots, V)$ for fuzzy demand constraints are given below (Amid et al., 2006):

$$
\begin{aligned}
& F\left(Z_{l}(x)\right)=\left\{\begin{array}{cc}
1 & \text { if } Z_{l}(x) \leq Z_{l}^{-} \\
\frac{Z_{l}^{+}-Z_{l}(x)}{Z_{l}^{+}-Z_{l}^{-}} & \text {if } Z_{l}^{-} \leq Z_{l}(x) \leq Z_{l}^{+} \\
0 & \text { if } Z_{l}(x) \geq Z_{l}^{+}
\end{array}\right. \\
& F\left(Z_{k}(x)\right)=\left\{\begin{array}{cc}
1 & \text { if } Z_{k}(x) \geq Z_{k}^{+} \\
\frac{Z_{k}(x)-Z_{k}^{-}}{Z_{k}^{+}-Z_{k}^{-}} & \text {if } Z_{k}^{-} \leq Z_{k}(x) \leq Z_{k}^{+} \\
0 & \text { if } Z_{k}(x) \leq Z_{k}^{-}
\end{array}\right. \\
& F\left(M_{v}(x)\right)=\left\{\begin{array}{cc}
\frac{M_{v}(x)-M_{v}^{-}}{\overline{M_{v}-M_{v}^{-}}} & \text {if } M_{v}^{-}<M_{v}(x) \leq \overline{M_{v}} \\
\frac{M_{v}^{+}-M_{v}(x)}{M_{v}^{+}-\overline{M_{v}}} & \text { if } \overline{M_{v}} \leq M_{v}(x)<M_{v}^{+} \\
0 & \text { if } M_{v}(x) \leq M_{v}^{-} \text {or } M_{v}(x) \geq M_{v}^{+}
\end{array}\right.
\end{aligned}
$$

In equations (13)-(15), $l=1,2, \ldots, P, k=1,2$, $\ldots, G$ and $v=1,2, \ldots, V$.

Step 5. Obtain $R$ groups of objective weights by the procedures presented in Figure 2. Here, the weight of demand constraint $\varphi_{v}(v=1,2, \ldots, V)$ is a determined parameter obtained from decision maker.

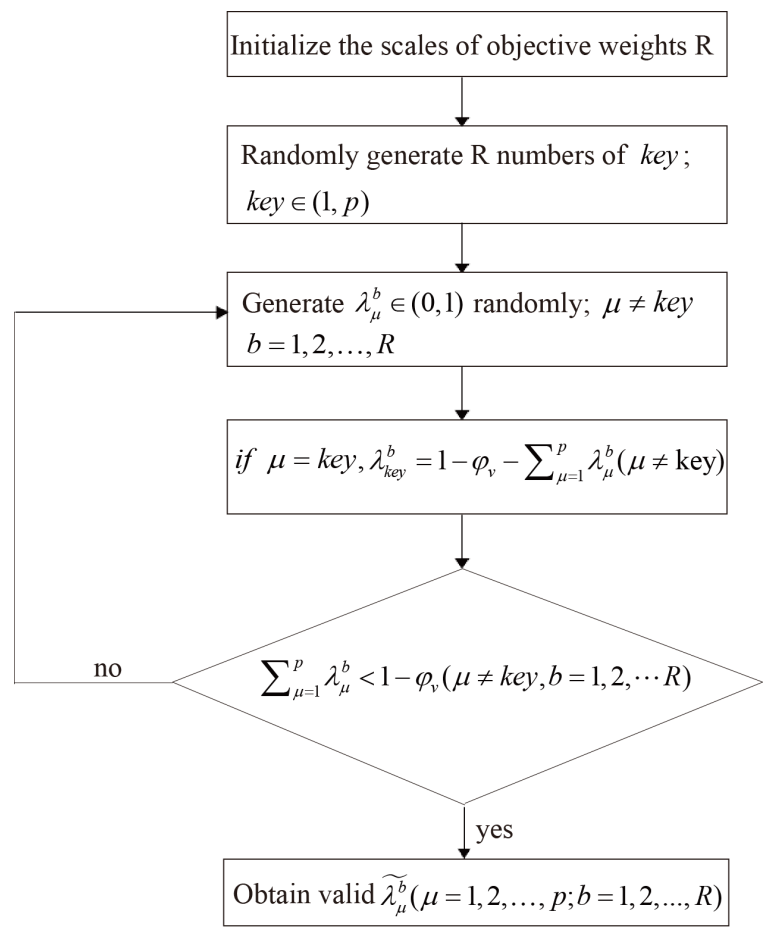

Note: $p$ : Numbers for the objectives; $\lambda_{\mu}^{b}$ : Weight for $\mu$-th objective of the b-th group; $\widetilde{\lambda_{\mu}^{b}}$ : Valid weight for $\mu$-th objective of the b-th group.

Figure 2. Procedures for generating the weights of objectives

Step 6. Reformulate the model as a single objective model by aggregating the weighted achievement levels ( $Y u$ et al., 2012) for each weight group $b(b=1,2, \ldots, R)$. In the expression (16), $g_{\mu}(\mu=1,2, \ldots, p)$ stands for the achievement level for the objectives and $d_{v}(v=1,2, \ldots, Q)$ stands for the achievement level for the demand constraints.

$$
\begin{aligned}
& \operatorname{Max} \sum_{\mu=1}^{\mu=p} g_{\mu} \lambda_{\mu}^{b}+\sum_{v=1}^{v=V} d_{v} \varphi_{v} \\
& g_{\mu} \leq F\left(Z_{\mu}(x)\right), \mu=1,2, \ldots, p \\
& d_{v} \leq F\left(M_{v}(x)\right), v=1,2, \ldots, V \\
& g_{\mu}, d_{v} \in[0,1], \mu=1,2, \ldots, p, \quad v=1,2, \ldots, V \\
& \sum_{\mu=1}^{p} g_{\mu}+\sum_{v=1}^{V} d_{v}=1, g_{\mu}, d_{v} \geq 0
\end{aligned}
$$

Step 7. Solve the single objective model and find the optimal solution $\delta^{*}$ by using the following expression:

$$
\delta^{*}=\arg \max \left(\sum_{\mu=1}^{\mu=p} g_{\mu} \lambda_{\mu}^{b}\left(\delta_{h}\right)+\sum_{v=1}^{v=V} d_{v} \varphi_{v}\left(\delta_{h}\right)\right), \delta^{*}, \delta_{h} \in S
$$


where $S=\left\{\delta_{1}, \delta_{2}, \ldots, \delta_{H}\right\}$ is the optimal solution set consisting of $H(H \leq R)$ groups of valid optimal solution $\delta_{h}(h=1,2, \ldots, H) \quad$ obtained from equation (16).

Step 8. Judge whether the solution $\delta^{*}$ is acceptable and the corresponding objective weight $\lambda_{\mu}^{b^{*}}$ is available or not. If $\delta^{*}$ is not acceptable or $\lambda_{\mu}^{b^{*}}$ is unavailable, then we adjust the range of $\lambda_{\mu}^{b}$ and then go to the step 7; if $\delta^{*}$ is acceptable and $\lambda_{\mu}^{b^{*}}$ is available, then a proposed solution is obtained.

The algorithm proposed in this paper introduces procedures for generating the weights of objectives which is the core technique improving the previous approach, the purpose of that is to make the algorithm feasible for the situations when the objective weights are uncertain. In this algorithm, the scale of the weight group $R$ is given by the decision maker which is usually a large positive integer, so that all possible weight senses for objectives are included.

\section{Case Study: A Real Application for Order Allocation in Automotive Industry}

\subsection{Problem Description}

In this subsection, the model is applied in the case of SOKON Industry Corporation Ltd of China.
The company needs to select no more than three suppliers from seven candidate suppliers and purchase four automotive sensor parts A to D including "temperature sensor", "fuel sensor", "knock sensor" and "pressure sensor". The company requests that the sensor parts supplied by the suppliers must meet the requirements of industry 4.0. The decision maker wishes to optimize three important goals including total cost minimization, unqualified parts minimization and reliability maximization. In this case, the decision maker considers that reliability is the most important, cost is of second importance and quality is the last important. The specific objective weight values are uncertain for decision makers. The demand for each part is hard to be precisely determined and the fuzzy demand is expressed as "pessimistic", "most likely" and "optimistic". The purchasing manager gives the values of triangular demand for the four parts that are A $(2420,2620$, 2720), B $(2320,2520,2670), C(1820,2120$, $2370)$, and $D(1770,2020,2220)$. If buyers choose a supplier, the orders should be greater than the minimum value $(200,200,160,180,170,140$, $165)$ for each of the candidate suppliers. Experts of the company define evaluation criteria for supplier reliability performance containing financial, technique and production, quality, service and product environment. The details of evaluation and the weights of the evaluation criteria are given in Table 2.

Table 2. Evaluation criteria for supplier reliability performance

\begin{tabular}{|l|l|c|}
\hline Criteria & \multicolumn{1}{|c|}{ Details of evaluation } & Weights \\
\hline \multirow{5}{*}{ Financial (C1) } & $\begin{array}{l}\text { 1. Business volume and profitability in the past three years } \\
\text { 2. Total value of fixed assets } \\
\text { 3.Scale of borrowing and asset-liability ratio } \\
\text { 4. The possibility of being acquired } \\
\text { 5. Whether overly dependent on a few large customers } \\
\text { 6. Whether own sufficient capital to complete the orders }\end{array}$ & 25 \\
\hline \multirow{3}{*}{$\begin{array}{l}\text { Technique and production } \\
\text { (C2) }\end{array}$} & $\begin{array}{l}\text { 1. Maintenance and ageing degree of production equipment } \\
\text { 2. Production capacity } \\
\text { 3. Response and flexibility to urgent or additional demand } \\
\text { 4.The ability technical innovation for future requirement }\end{array}$ & 20 \\
\hline \multirow{2}{*}{ Quality (C3) } & $\begin{array}{l}\text { 1. The proportion of products satisfying ISO 9000 standard } \\
\text { 2. The advancement and reliability of products } \\
\text { 3. Suitability of products }\end{array}$ & 25 \\
\hline Service (C4) & $\begin{array}{l}\text { 1. Return unqualified products in time } \\
\text { 2. Deliver products within allowable time } \\
\text { 3. Average number of products delivered from suppliers to purchasers within given time }\end{array}$ & 15 \\
\hline Product environment (C5) & $\begin{array}{l}\text { 1. Green design } \\
\text { 2. Stable environmental management system including ISO 14001, EMAS }\end{array}$ & 15 \\
\hline
\end{tabular}


Then experts give the evaluation scores of the candidate suppliers, and the original scores of the supplier stability performance are given in Table 3. By calculating the ratio of sum score of the criteria $\mathrm{C} 1-\mathrm{C} 5$ to the total weights of these criteria, the reliability performance coefficients for the candidate suppliers are obtained as follows: $(0.93,0.95,0.94,0.93,0.93,0.95,0.92)$.

Table 3. Original evaluation score of supplier reliability performance

\begin{tabular}{c|ccccc}
\hline \multirow{2}{*}{ Supplier } & \multicolumn{5}{|c}{ Score of reliability performance } \\
\cline { 2 - 6 } & C1 & C2 & C3 & C4 & C5 \\
\hline 1 & 23 & 19 & 24 & 13 & 14 \\
2 & 22 & 19 & 25 & 14 & 15 \\
3 & 24 & 19 & 24 & 13 & 14 \\
4 & 25 & 18 & 23 & 13 & 14 \\
5 & 23 & 19 & 24 & 14 & 13 \\
6 & 24 & 19 & 24 & 14 & 14 \\
7 & 23 & 19 & 24 & 13 & 13 \\
\hline
\end{tabular}

Fixed and variable costs for the four automotive parts are given in Table 4. In this case, each candidate supplier provides the four sensor parts and suppliers' triangular fuzzy production capacity for the parts A to D are given in Table 5.
Table 4. Fixed and variable costs of the automotive parts A-D

\begin{tabular}{c|cccc|c}
\hline \multirow{2}{*}{ Supplier } & \multicolumn{4}{|c|}{ Unit variable cost for automotive parts } & Fixed \\
\cline { 2 - 5 } & A & C & B & D & cost \\
\hline 1 & 32 & 176 & 23 & 250 & 1300 \\
2 & 50 & 185 & 30 & 235 & 1200 \\
3 & 47 & 190 & 42 & 220 & 1500 \\
4 & 39 & 198 & 26 & 245 & 1600 \\
5 & 31 & 170 & 38 & 247 & 1000 \\
6 & 37 & 171 & 40 & 237 & 1100 \\
7 & 45 & 183 & 45 & 243 & 1350 \\
\hline
\end{tabular}

The defect rate for the automotive parts is inaccurate in production and the triangular fuzzy defect rates for the automotive parts of the seven candidate suppliers are given in Table 6. To reduce excessive dependence on a supplier and reduce the risk, buyer limits the variable cost of purchasing from a supplier through the value of variable costs in historical transactions with suppliers. The upper limit values of variable costs from the candidate suppliers are $(¥ 510000, ¥ 520000, ¥ 530000$, $¥ 560000 ; ¥ 550000 ; ¥ 520000 ; ¥ 390000$ ).

In order to encourage buyers to purchase more automotive parts, candidate suppliers propose allunit quantity discounts that are shown in Table 7. The minimum orders for the seven candidate suppliers are $(200,200,160,180,170,145,165)$.

Table 5. Triangular fuzzy capacity of suppliers for the parts A-D

\begin{tabular}{|c|c|c|c|c|c|c|c|c|c|c|c|c|}
\hline \multirow{2}{*}{ Supplier } & \multicolumn{3}{|c|}{ A } & \multicolumn{3}{|c|}{$\mathrm{B}$} & \multicolumn{3}{|c|}{ C } & \multicolumn{3}{|c|}{ D } \\
\hline & $\mathrm{P}$ & $\mathrm{M}$ & $\mathrm{O}$ & $\mathrm{P}$ & $\mathrm{M}$ & $\mathrm{O}$ & $\mathrm{P}$ & M & $\mathrm{O}$ & $\mathrm{P}$ & $\mathrm{M}$ & $\mathrm{O}$ \\
\hline 1 & 1770 & 1920 & 2020 & 1670 & 1720 & 2030 & 1370 & 1420 & 1720 & 1280 & 1430 & 1530 \\
\hline 2 & 1670 & 1820 & 1920 & 1570 & 1820 & 2070 & 1320 & 1470 & 1670 & 1370 & 1530 & 1730 \\
\hline 3 & 1720 & 1770 & 1820 & 1670 & 1770 & 1920 & 1470 & 1670 & 1820 & 1480 & 1630 & 1830 \\
\hline 4 & 1870 & 1920 & 2070 & 1770 & 1920 & 2120 & 1270 & 1520 & 1770 & 1880 & 1930 & 2080 \\
\hline 5 & 1520 & 1770 & 2030 & 1620 & 1870 & 2170 & 1420 & 1620 & 1870 & 1780 & 1980 & 2130 \\
\hline 6 & 1920 & 2030 & 2130 & 1570 & 1720 & 1970 & 1520 & 1720 & 1820 & 1580 & 1730 & 1930 \\
\hline 7 & 1970 & 2120 & 2220 & 1820 & 1920 & 2120 & 1630 & 1780 & 1930 & 1430 & 1580 & 1730 \\
\hline
\end{tabular}

Note: A: temperature sensor; B: fuel sensor; C: knock sensor; D: pressure sensor; P: Pessimistic; M: Most likely; O: Optimistic

Table 6. Triangular fuzzy defect rate for the automotive parts A-D

\begin{tabular}{|c|c|c|c|c|c|c|c|c|c|c|c|c|}
\hline \multirow{2}{*}{ Supplier } & \multicolumn{3}{|c|}{ A } & \multicolumn{3}{|c|}{$\mathrm{B}$} & \multicolumn{3}{|c|}{$\mathrm{C}$} & \multicolumn{3}{|c|}{ D } \\
\hline & $\mathrm{P}$ & $\mathrm{M}$ & $\mathrm{O}$ & $\mathrm{P}$ & M & $\mathrm{O}$ & $\mathrm{P}$ & M & $\mathrm{O}$ & $\mathrm{P}$ & $\mathrm{M}$ & $\mathrm{O}$ \\
\hline 1 & 0.041 & 0.031 & 0.012 & 0.035 & 0.020 & 0.011 & 0.051 & 0.036 & 0.018 & 0.049 & 0.034 & 0.016 \\
\hline 2 & 0.037 & 0.025 & 0.010 & 0.042 & 0.027 & 0.018 & 0.028 & 0.014 & 0.004 & 0.030 & 0.016 & 0.005 \\
\hline 3 & 0.035 & 0.023 & 0.008 & 0.051 & 0.036 & 0.020 & 0.036 & 0.026 & 0.011 & 0.032 & 0.017 & 0.006 \\
\hline 4 & 0.050 & 0.035 & 0.017 & 0.033 & 0.018 & 0.009 & 0.045 & 0.035 & 0.017 & 0.035 & 0.018 & 0.007 \\
\hline 5 & 0.043 & 0.033 & 0.015 & 0.030 & 0.016 & 0.006 & 0.034 & 0.019 & 0.010 & 0.037 & 0.020 & 0.009 \\
\hline 6 & 0.030 & 0.015 & 0.007 & 0.029 & 0.015 & 0.005 & 0.027 & 0.015 & 0.005 & 0.039 & 0.022 & 0.010 \\
\hline 7 & 0.032 & 0.017 & 0.009 & 0.044 & 0.033 & 0.016 & 0.029 & 0.017 & 0.007 & 0.041 & 0.024 & 0.012 \\
\hline
\end{tabular}

Note: A: temperature sensor; B: fuel sensor; C: knock sensor; D: pressure sensor; P: Pessimistic; M: Most likely; O: Optimistic

https://www.sic.ici.ro 
Table 7. All-unit quantity discounts provided by candidate suppliers

\begin{tabular}{cc|c}
\hline Supplier & Quantity & Discounts \\
\hline 1 & {$[0,1100) ;[1100,2200) ;[2100,3100) ;[3100,+\infty)$} & $0.0 \% ; 7.3 \% ; 11.6 \% ; 16.6 \%$ \\
2 & {$[0,900) ;[900,1900) ;[1900,2900) ;[2900,+\infty)$} & $0.0 \% ; 6.1 \% ; 10.5 \% ; 15.6 \%$ \\
3 & {$[0,750) ;[750,1750) ;[1750,2750) ;[2750,+\infty)$} & $0.0 \% ; 8.1 \% ; 11.8 \% ; 16.9 \%$ \\
4 & {$[0,870) ;[870,1870) ;[1870,2870) ;[2870,+\infty)$} & $0.0 \% ; 6.7 \% ; 11.0 \% ; 16.0 \%$ \\
5 & {$[0,1220) ;[1220,2220) ;[2220,3220) ;[3220,+\infty)$} & $0.0 \% ; 9.1 \% ; 12.2 \% ; 17.0 \%$ \\
6 & {$[0,680) ;[680,1680) ;[1680,2680) ;[2680,+\infty)$} & $0.0 \% ; 5.7 \% ; 10.1 \% ; 15.0 \%$ \\
7 & {$[0,950) ;[950,1950) ;[1950,2950) ;[2950,+\infty)$} & $0.0 \% ; 6.3 \% ; 10.8 \% ; 15.9 \%$ \\
\hline
\end{tabular}

\subsection{Order Allocations for Suppliers}

In this subsection, the fuzzy MOMIP model is built and the interactive algorithm is used to solve the model according to the methodology mentioned in Section 3. The steps of the algorithm to solve the model are as follows:

Step 1. Defuzzify the triangular fuzzy values of demand, defect rate and capacity. The defuzzification of demand for parts $\mathrm{A}$ to $\mathrm{D}$ is (2586.7, 2503.3, 2103.3, 2003.3). The values of defuzzification of defect rate and production capacity for the parts A-D are shown in Tables 8-9.

Table 8. Defuzzification of defect rate for the parts A to $\mathrm{D}$

\begin{tabular}{c|c|c|c|c}
\hline Supplier & A & B & C & D \\
\hline 1 & 0.028 & 0.022 & 0.035 & 0.033 \\
2 & 0.024 & 0.029 & 0.015 & 0.017 \\
3 & 0.022 & 0.036 & 0.024 & 0.018 \\
4 & 0.034 & 0.020 & 0.032 & 0.020 \\
5 & 0.030 & 0.017 & 0.021 & 0.022 \\
6 & 0.017 & 0.016 & 0.016 & 0.024 \\
7 & 0.019 & 0.031 & 0.018 & 0.026 \\
\hline
\end{tabular}

Note: A: temperature sensor; B: fuel sensor; C: knock sensor; D: pressure sensor

Table 9. Defuzzification of capacity for the parts A to $\mathrm{D}$

\begin{tabular}{c|c|c|c|c}
\hline Supplier & A & B & C & D \\
\hline 1 & 1903.3 & 1806.7 & 1503.3 & 1413.3 \\
2 & 1803.3 & 1820 & 1486.7 & 1543.3 \\
3 & 1770 & 1786.7 & 1653.3 & 1646.7 \\
4 & 1953.3 & 1936.7 & 1520 & 1963.3 \\
5 & 1773.3 & 1886.7 & 1636.7 & 1963.3 \\
6 & 2026.7 & 1753.3 & 1686.7 & 1746.7 \\
7 & 2103.3 & 1953.3 & 1780 & 1580 \\
\hline
\end{tabular}

Note: A: Temperature sensor; B: fuel sensor; C: knock sensor; D: pressure sensor
Step 2. Solve a single objective model by using the max-min approach (Zimmermann, 1978) for each objective of the model separately. The maximum and minimum values for each objective are shown in Table 10.

Table 10. Maximize and minimize objective values for objectives

\begin{tabular}{c|c|c|c}
\hline Supplier & Cost $(¥)$ & Quality & Reliability \\
\hline Max & 2289325.0 & 476.6 & 20294.6 \\
Min & 964914.1 & 155.3 & 8811.0 \\
\hline
\end{tabular}

Step 3. Establish membership functions for the three fuzzy objectives and fuzzy demand constraints. The graphical membership functions are shown in Figures 3 and 4.
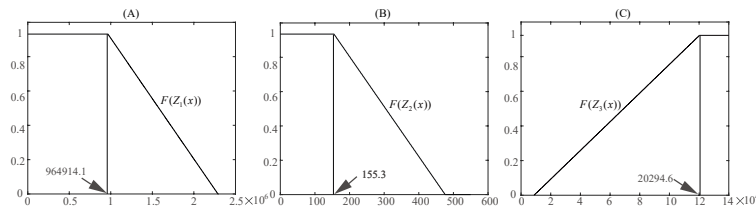

Note: (A): Cost; (B): Quality; (C): Reliability

Figure 3. Membership functions for three objectives: cost, quality and reliability

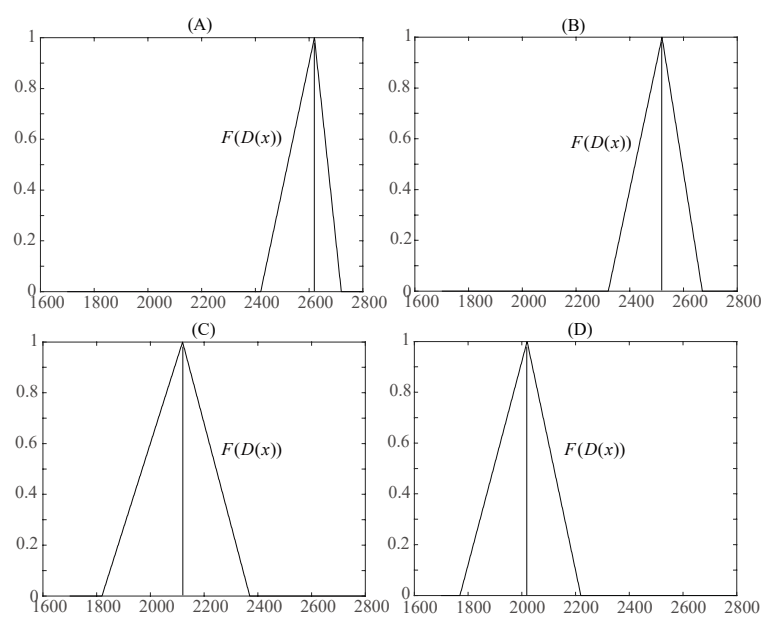

Note: (A): Temperature sensor; (B): fuel sensor; (C): knock sensor; D: pressure sensor

Figure 4. Membership functions of demand functions for the automotive parts $\mathrm{A}$ to $\mathrm{D}$ 
Step 4. Generate 1400 groups of objective weights by the weight generation method proposed in Section 3. The weight for demand constraint is assumed as 0.15 by decision makers and it remains unchanged. The distribution of 1400 group's objective weights for cost, quality and reliability is shown in Figure 5.

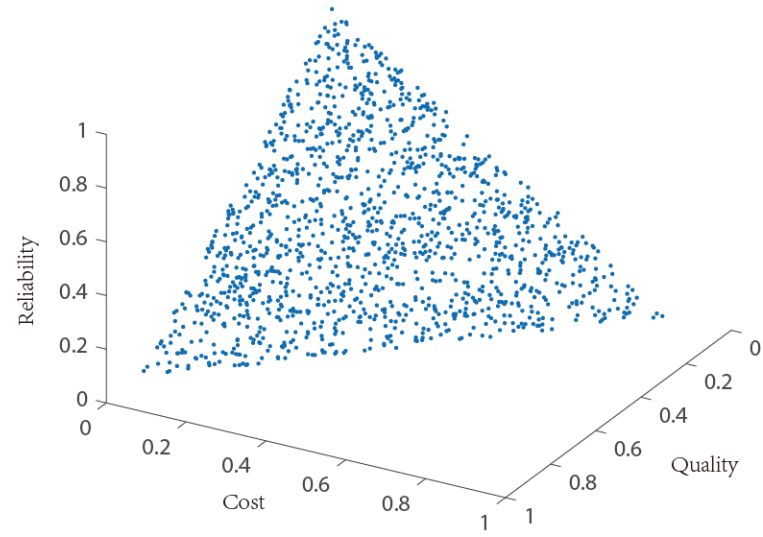

Figure 5. Distribution of objective weights for cost, quality and reliability

Step 5. Reformulate the fuzzy multi-objective programming model as a crisp single objective model. The model has been solved on a Pentium $(2.9 \mathrm{GHz})$ personal computer. The solutions for the model are computed by using LINGO 15.0.

Step 6. Apply the single objective model obtained for 1400 groups of objective weights obtained in step 4. After removing the weight groups without solutions, 1246 valid optimal solutions are obtained. The result of the ascending sort of the three objectives and the overall achievement levels for the valid solutions are shown in Figure 6.
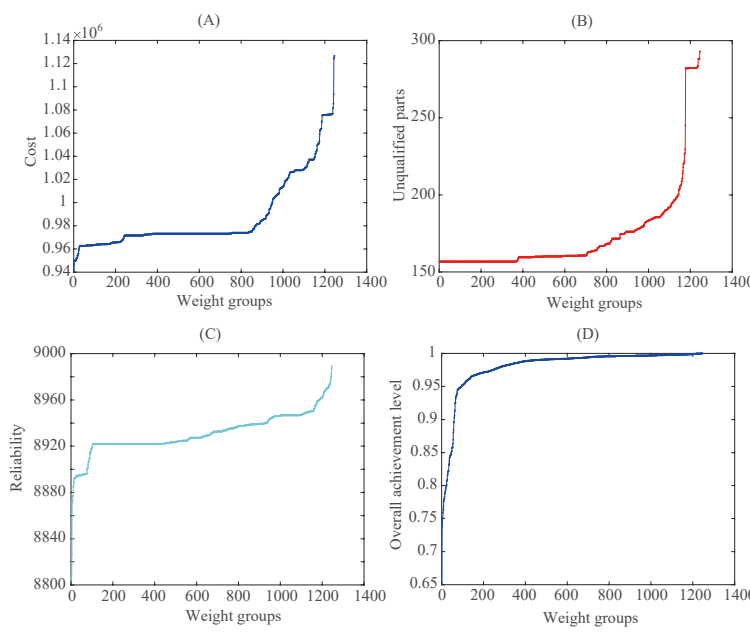

Figure 6. Ascending sort of the three objectives and overall achievement levels for valid solutions
Step 6. Apply the single objective model obtained for 1400 groups of objective weights obtained in step 4. After removing the weight groups without solutions, 1246 valid optimal solutions are obtained. The result of the ascending sort of the three objectives and the overall achievement levels for the valid solutions are shown in Figure 6.

Step 7. According to equation (21), the maximum value of the overall achievement level is obtained and it is $99.9 \%$. The optimal objective weights for the three objectives are $(0.039,0.006$, 0.805 ) which is consistent with preference order described in subsection 4.1. Finally, the decision makers obtain the satisfactory solution of the optimal order allocations which is shown in Table 11.

Table 11. Solution of the optimal order allocations for the A to D automotive parts

\begin{tabular}{c|ccccccc|c}
\hline \multirow{2}{*}{ Part } & \multicolumn{7}{|c|}{ Orders for suppliers } & Objective \\
\cline { 2 - 7 } & 1 & 2 & 3 & 4 & 5 & 6 & 7 & values \\
\hline A & 0 & 0 & 0 & 0 & 0 & 2026 & 641 & $\mathrm{Z}_{1}=964331.6$ \\
$\mathrm{~B}$ & 0 & 0 & 0 & 0 & 809 & 1753 & 0 & \\
$\mathrm{C}$ & 0 & 1486 & 0 & 0 & 0 & 667 & 0 & $\mathrm{Z}_{2}=159.9$ \\
$\mathrm{D}$ & 0 & 1543 & 0 & 0 & 0 & 516 & 0 & $\mathrm{Z}_{3}=8933.5$ \\
\hline
\end{tabular}

\section{Discussions}

The validity of the proposed model is verified in this section. Firstly, the optimal supplier selection and order allocations and objective values with uncertain objective weights are analyzed, then the uncertain objective weights are divided into four categories. Secondly, the overall achievement level and optimal order allocations for different preference orders of objective weights are discussed. The two important aspects are elaborated below.

\subsection{Solutions and Objective Values Analysis with Uncertain Objective Weights}

In this subsection, the objective weights generated from Section 4 are divided into four categories and the ranges of the weight for reliability for the four categories are $[0,0.2),[0.2,0.4),[0.4,0.6)$ and $[0.6,0.85]$. The weight ranges for cost, quality and reliability are shown in Table 12 and the distribution of the weights for the three objectives is displayed in Figure 7. 
Table 12. Weight range for cost, quality and reliability for the four categories

\begin{tabular}{c|c|c|c|c}
\hline \multirow{2}{*}{ Category } & \multicolumn{3}{|c|}{ Weight range (min, max) } & \multirow{2}{*}{ Scale } \\
\cline { 2 - 4 } & Cost & Quality & Reliability & \\
\hline \multirow{2}{*}{ (a) } & $\left(1.7 \times 10^{-4}\right.$, & $\left(0.2 \times 10^{-4}\right.$, & $\left(3.4 \times 10^{-4}\right.$, & \multirow{2}{*}{544} \\
& $0.83)$ & $0.83)$ & $0.20)$ & \\
(b) & $\left(0.9 \times 10^{-4}\right.$, & $\left(6.5 \times 10^{-4}\right.$, & $\left(2.0 \times 10^{-1}\right.$, & 447 \\
& $0.64)$ & $0.61)$ & $0.40)$ & \\
(c) & $\left(3.6 \times 10^{-3}\right.$, & $\left(0.2 \times 10^{-4}\right.$, & $\left(4.0 \times 10^{-1}\right.$, & 270 \\
& $0.43)$ & $0.42)$ & $0.60)$ & \\
(d) & $\left(2.7 \times 10^{-4}\right.$, & $\left(2.6 \times 10^{-4}\right.$, & $\left(6.0 \times 10^{-1}\right.$, & \multirow{2}{*}{139} \\
\hline
\end{tabular}

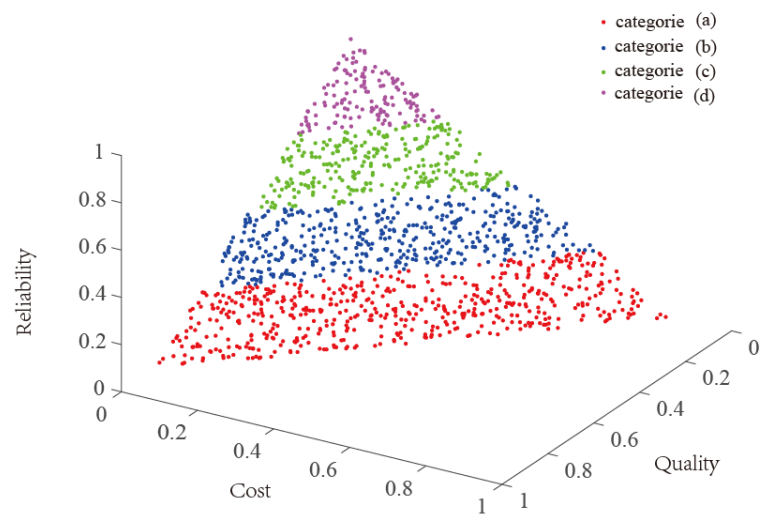

Figure 7. Distribution of weights for cost, quality and reliability for the four categories

Then, the model proposed in Section 3 is applied for the four weight categories and the optimal solutions and optimal cost, unqualified parts and reliability values are obtained as shown in Table 13. From the result, it is obvious that the solutions of the optimal order allocations are the same for categories (b) and (d), in which the suppliers 6, 7 are selected for part A, the suppliers 5,6 are selected for part B, the suppliers 2, 6 are selected for parts $\mathrm{C}$ and D. Meanwhile, the supplier selection for parts A to D of category (a) is consistent with that of categories (b) and (d). The supplier selection for parts A, B, C for category (c) is consistent with that for categories (a), (b) and (d), but different for part $\mathrm{D}$ in which the supplier 3 is selected.

It is worth mentioning that decision makers always wish to predict cost, quality and reliability in the procurement. In order to analyze the most probably values of cost, unqualified parts and reliability when the objective weights are uncertain, the frequency for the values of the three objectives is computed for the valid solutions obtained by applying the model for the categorized weights displayed in Figure 7. The distribution of frequency for the values of the three objectives for the four categories is displayed in Figures 8 to 10.

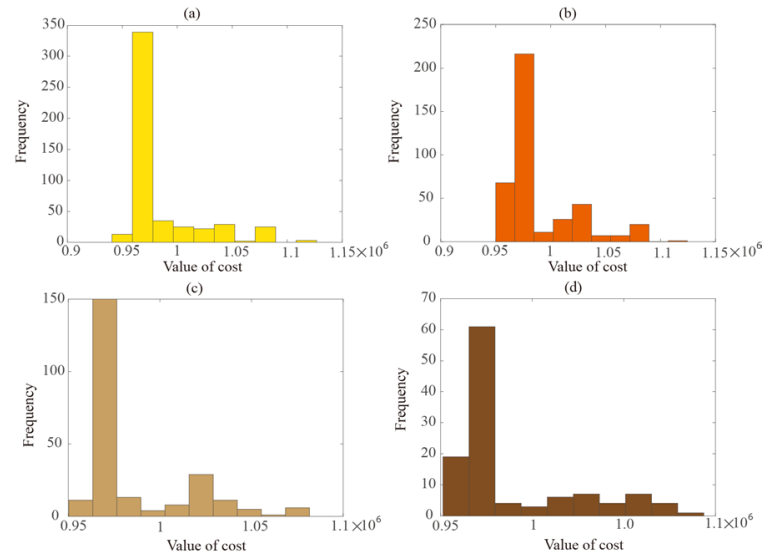

Figure 8. Frequency distribution of cost for the weight categories (a) to (d)

Table 13. Solution of the optimal order allocations for the A to D automotive parts

\begin{tabular}{c|c|ccccccc|c}
\hline \multirow{2}{*}{ Category } & \multirow{7}{*}{ Part } & \multicolumn{7}{|c|}{ Orders for suppliers } & \multirow{2}{*}{ Objective values } \\
\cline { 3 - 8 } & & 1 & 2 & 3 & 4 & 5 & 6 & 7 & \\
\hline \multirow{5}{*}{ (a) } & $\mathrm{A}$ & 0 & 0 & 0 & 0 & 0 & 2026 & 641 & $\mathrm{Z}_{1}=964130.1$ \\
& $\mathrm{~B}$ & 0 & 0 & 0 & 0 & 809 & 1753 & 0 & \\
& $\mathrm{C}$ & 0 & 1486 & 0 & 0 & 0 & 667 & 0 & $\mathrm{Z}_{2}=159.9$ \\
& $\mathrm{D}$ & 0 & 1543 & 0 & 0 & 0 & 515 & 0 & $\mathrm{Z}_{3}=8932.6$ \\
\hline \multirow{5}{*}{ (b), (d) } & $\mathrm{A}$ & 0 & 0 & 0 & 0 & 0 & 2026 & 641 & $\mathrm{Z}_{1}=964331.6$ \\
& $\mathrm{~B}$ & 0 & 0 & 0 & 0 & 809 & 1753 & 0 & \\
& $\mathrm{C}$ & 0 & 1486 & 0 & 0 & 0 & 667 & 0 & $\mathrm{Z}_{2}=159.9$ \\
& $\mathrm{D}$ & 0 & 1543 & 0 & 0 & 0 & 516 & 0 & $\mathrm{Z}_{3}=8933.5$ \\
\hline \multirow{5}{*}{ (c) } & $\mathrm{A}$ & 0 & 0 & 0 & 0 & 0 & 2026 & 640 & $\mathrm{Z}_{1}=964331.6$ \\
& $\mathrm{~B}$ & 0 & 0 & 0 & 0 & 809 & 1752 & 0 & \\
& $\mathrm{C}$ & 0 & 1486 & 0 & 0 & 0 & 666 & 0 & $\mathrm{Z}_{2}=159.9$ \\
& $\mathrm{D}$ & 0 & 1543 & 512 & 0 & 0 & 0 & 0 & $\mathrm{Z}_{3}=8933.5$ \\
\hline
\end{tabular}



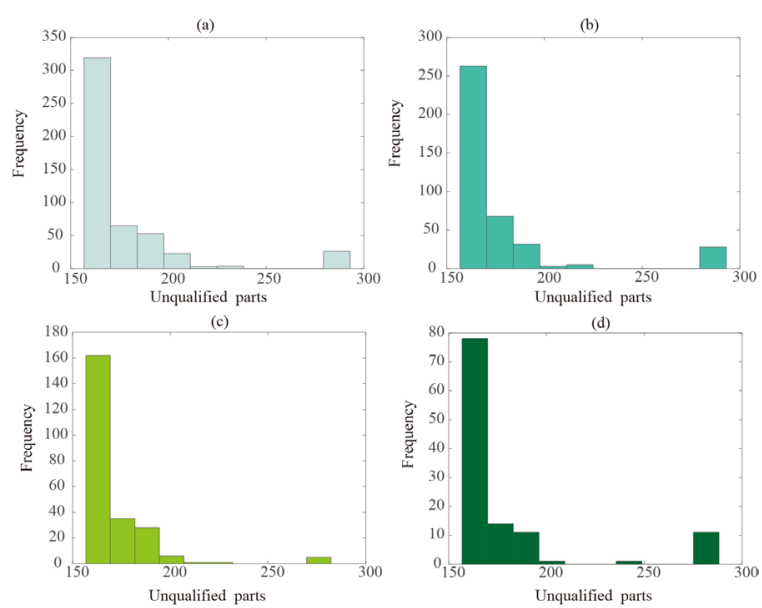

Figure 9. Frequency distribution of quality for the weight categories (a) to (d)
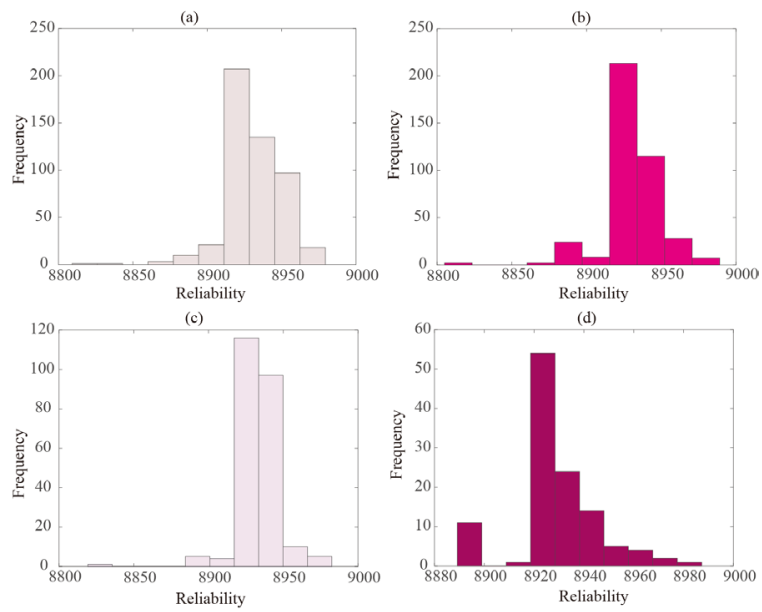

Figure 10. Frequency distribution of reliability for the weight categories (a) to (d)

From the results, it can be observed that most of frequency distribution of cost varies between ( $¥ 95900$, ¥97800), (¥96700, ¥98500), (¥96300, ¥97600), (¥96500, ¥98000) for the weight categories (a) to (d). Most of frequency distribution of unqualified parts varies between $(156.8,170)$ for the weight categories (a), (b) and $(d)$, and $(156.8,169)$ for category (c). Most of frequency distribution of reliability value for the weight categories $\mathrm{B}, \mathrm{C}$ and $\mathrm{D}$ varies between (8920, 8930), and between $(8910,8930)$ for category (a). These most frequency distribution values of cost, unqualified parts and reliability for the weight categories (a) to (d) provide valuable information for decision makers.

Then, the maximum and minimum values of cost, quality and reliability with uncertain weights are obtained as shown in Figure 11. The result shows that the rise of weight of reliability dominates the decline of the maximum value of cost and unqualified parts, under the opposite internal effect between quality and cost. Simultaneously, the result also implies that the rise of weight of reliability doesn't affect the minimum value of unqualified parts, but dominates the rise of the minimum value of cost and reliability performance.
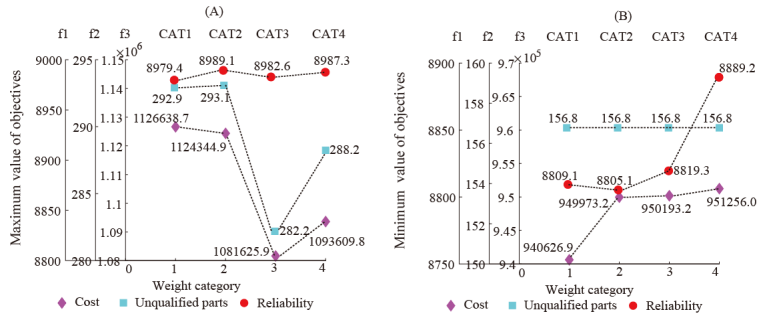

Note : f1: Reliability; f2: Unqualified parts; f3: Cost; CAT1: Weight category (a);

CAT2: Weight category (b); CAT3: Weight category (c); CAT4: Weight category (d)

Figure 11. Maximum and minimum value of three objectives with uncertain weights

From the results, the minimum value of cost is $¥ 940626.9$ which can be obtained in the weight scene $(0.49,0.20,0.16)$; the maximum value of reliability is 8989.1 and it can be obtained in the weight scene $(0.37,0.21,0.27)$; the minimum value of unqualified parts is 156.8 , and it can be obtained in non-uniqueness weight senses as shown in Figure 12. The result shows that the weight scenes for the optimal value of quality are non-unique, but when the cost or reliability are optimal, the weight scene is unique. From the result, it is clear that among the weight scenes for the minimum unqualified parts, the weight value of cost is all lower than 0.45 , which proves that high quality is always at the expense of cost.

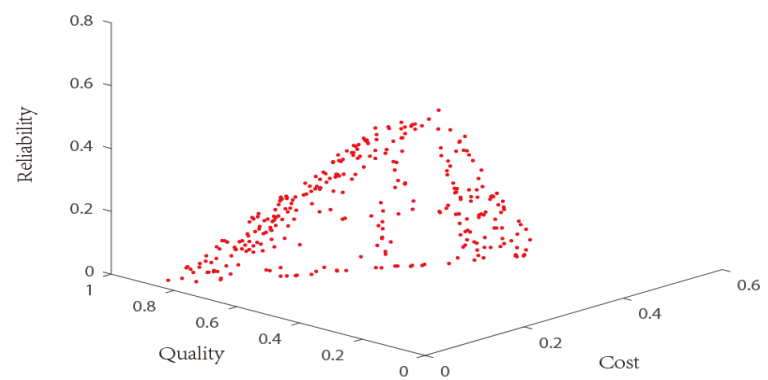

Figure 12. Objective weights for the minimum unqualified parts 


\subsection{Overall Achievement Level and Order Allocations for Different Preference Orders of Objective Weights}

Since the overall achievement level is a vital factor in selecting suppliers and order allocations, the overall achievement levels of objectives are computed for the weight categories (a) to (d) which have been mentioned in subsection 5.1. The results are shown in Figure 13. It is clear that the overall achievement level is gradually increasing from the weight categories (a) to (d), and the maximum values of the achievement level for the four groups are all close to 1 and the minimum value is not lower than 0.65 for the four categories.

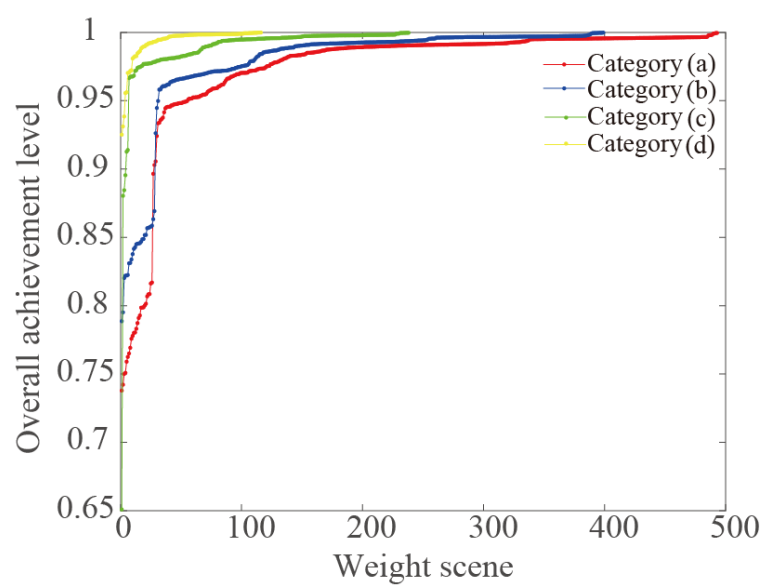

Figure 13. Overall achievement level for objectives for weight categories A to D

The achievement levels in category (d) are higher when compared to the other three categories, which may be caused by the highest weight of reliability in this category. In order to analyze the overall achievement level of the three objectives with different preference orders, the 1400 objective weights are classified into six scenarios (see Table 14).

Table 14. Preference order classification for all the objective weights

\begin{tabular}{c|c}
\hline Scenario & Preference orders for the objective weights \\
\hline (i) & $\mathrm{W} 3>\mathrm{W} 2>\mathrm{W} 1$ \\
\hline (ii) & $\mathrm{W} 3>\mathrm{W} 1>\mathrm{W} 2$ \\
\hline (iii) & $\mathrm{W} 2>\mathrm{W} 3>\mathrm{W} 1$ \\
\hline (iv) & $\mathrm{W} 1>\mathrm{W} 2>\mathrm{W} 3$ \\
\hline (v) & $\mathrm{W} 2>\mathrm{W} 1>\mathrm{W} 3$ \\
\hline (vi) & $\mathrm{W} 1>\mathrm{W} 3>\mathrm{W} 2$ \\
\hline
\end{tabular}

Note: W1: weight for cost; W2: Weight for quality; W3 Weight for reliability
Next, the overall achievement level and the corresponding order allocations for preference order classification of weight scenarios are obtained as shown in Figures 14-15. It is observed that the supplier selections and order allocations in the weight scenarios (ii) and (vi) are the same in which the suppliers 6 and 7 are selected for part A, the suppliers 5 and 6 for part $\mathrm{B}$, the suppliers 2 and 6 for parts $\mathrm{C}$ and $\mathrm{D}$. The total purchase quantity of the parts $\mathrm{B}, \mathrm{C}$ and $\mathrm{D}$ is $(2667,2562,2153,2059)$.

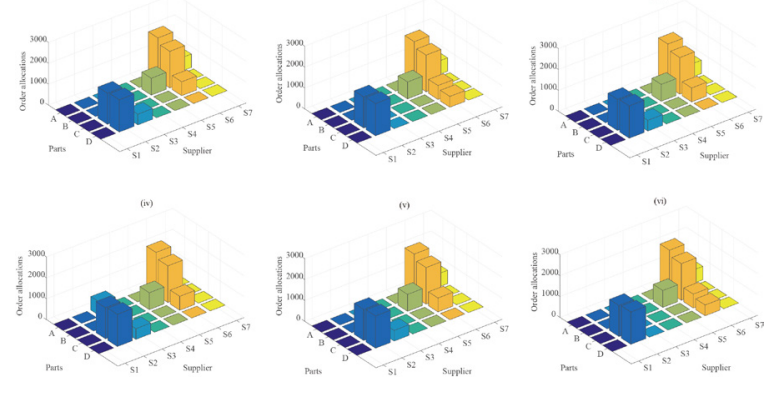

Figure 14. Optimal order allocations for the six weight scenarios of different preference orders

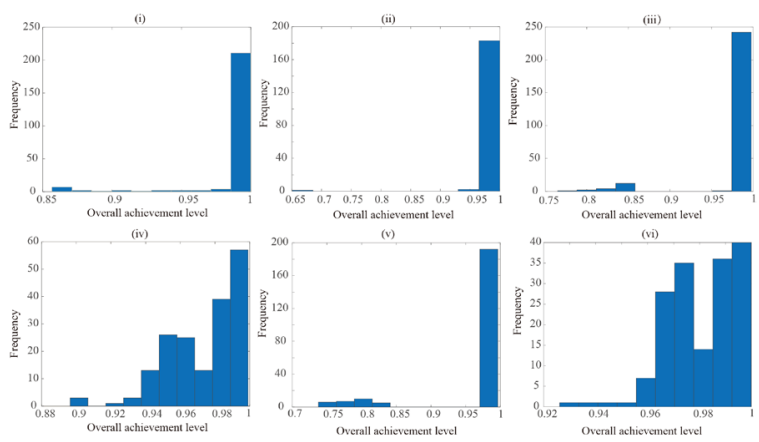

Figure 15. Overall achievement level for the six weight scenarios of different preference orders

The supplier selections of the weight scenarios (i), (iii) and (v) are the same but the total quantities of parts $\mathrm{A}, \mathrm{B}$ and $\mathrm{C}$ of the three scenarios are slightly different. The supplier selections and order allocations of the weight scenarios (iv) are different from those of the other scenarios.

From Figure 15, the overall achievement levels of almost all weight scenes are close to 1 in the preference order $\mathrm{W} 3>\mathrm{W} 2>\mathrm{W} 1, \mathrm{~W} 3>\mathrm{W} 1>\mathrm{W} 2$, $\mathrm{W} 2>\mathrm{W} 3>\mathrm{W} 1$ and $\mathrm{W} 2>\mathrm{W} 1>\mathrm{W} 3$, and distributed between 0.9 to 1 in $\mathrm{W} 1>\mathrm{W} 2>\mathrm{W} 3$, and between 0.92 to 1 in $\mathrm{W} 1>\mathrm{W} 3>\mathrm{W} 2$. The results indicate that excellent overall achievement level will be probably obtained when the decision makes consider the reliability or quality more important than cost, meanwhile inferior achievement level may be gained if the preference for cost is greater than that for quality and reliability. 


\section{Conclusion}

This paper proposes a multiple objective decisionmaking model for automotive parts purchasing for Chongqing SOKON Industry Group Stock Corporation Ltd in China. The model takes three purchasing objectives into consideration: total cost minimization, defective parts minimization and reliability maximization. A novel evaluation criteria system is adopted for obtaining supplier reliability performance and fuzzy factors. All-unit quantity discount and variable cost constraint are also considered in the model. For solving the model, an extended interactive algorithm which includes procedures is proposed for generating the weights of objectives when the preferences of objectives from decision makers are uncertain. The model is applied into a case of sensor parts purchasing for Chongqing SOKON Industry Group Stock Corporation Ltd and the validity of the proposed model is discussed. The results reveal that the proposed model can efficiently help decision makers to select suppliers and find optimal order allocations, and further predict the ranges for cost, quality and reliability when objective weights are uncertain. This paper has overcome three limitations:

1. Information loss of reliability is avoided by adopting a synthetical evaluation reliability system in obtaining the reliability performance, which improves the model.

2. The problem of inefficiency for finding the optimal solution for the fuzzy purchasing

\section{REFERENCES}

Amid, A., Ghodsypour, S. H. \& O’Brien, C. (2006). Fuzzy multiobjective linear model for supplier selection in a supply chain, International Journal of Production Economics, 104(2), 394-407.

Amid, A., Ghodsypour, S. H. \& O'Brien, C. (2009). A weighted additive fuzzy multiobjective model for the supplier selection problem under price breaks in a supply chain, International Journal of Production Economics, 121(2), 323-332.

Asdecker, B. \& Felch, V. (2018). Development of an Industry 4.0 maturity model for the delivery process in supply chains, Journal of Modelling in Management, 13(4), 840-883.

Baroudi, U. \& Haque, M. E. (2021). Ambient selfpowered cluster-based wireless sensor networks for model under uncertain weights is solved by integrating procedures for generating possible weights of objectives in the extended interactive algorithm.

3. Optimizing cost and quality together with comprehensive reliability which integrates multiple reliable criteria for auto-part suppliers in the model enable its usability for automotive industry.

For future research, the presented model can be investigated in the following directions: (1). The risk of automotive parts purchasing which may contain quality risk of raw materials or interruption of supply for the purchasing can be investigated as a part of the problem. (2). The price of automotive parts fluctuates with market changes could be worthy to be studied in the later work. (3). The inventory capacity limitation for the buyers could be a valuable factor to be investigated in extending the model.

The model in this paper can be transformed into a software and applied to the three scenarios. Firstly, the software can be applied when choosing suppliers for automotive manufacturer with longterm cooperation at the end of each quarter. Secondly, it can be applied to the situation that automotive enterprises need to evaluate the reliability of suppliers, and further adjust the order allocation to find the right solutions. Thirdly, the software can be used to predict total cost, supplier quality and stability in the context of rapid market changes, which further helps the decision maker avoiding risk in the future work.

industry 4.0 applications, Soft Computing, 25(4), $1859-1884$.

Caiado, R. G. G., Scavarda, L. F., Luiz Octávio Gavio, Ivson, P. \& Garza-Reyes, J. A. (2020). A fuzzy rulebased industry 4.0 maturity model for operations and supply chain management, International Journal of Production Economics, 231, 107883.

Chatterjee, K. \& Kar, S. (2018). Supplier selection in Telecom supply chain management: a FuzzyRasch based COPRAS-G method, Technological and Economic Development of Economy, 24(2), 765-791.

Chen, N. \& Xu, Z. S. (2015). Hesitant fuzzy ELECTRE II approach: A new way to handle multi-criteria decision making problems, Information Sciences, 292, 175-197. 
Dai, B., Nu, Y., Xie, X. \& Li, J. (2021). Interactions of traceability and reliability optimization in a competitive supply chain with product recall, European Journal of Operational Research, 290, 116-131.

Fazli-Khalaf, M., Naderi, B., Mohammadi, M. \& Pishvaee, M. S. (2020). Design of a sustainable and reliable hydrogen supply chain network under mixed uncertainties: a case study, International Journal of Hydrogen Energy, 45, 34503-34531.

Frank, A. G., Dalenogare, L. S., Ayala, N. F. (2019). Industry 4.0 technologies: implementation patterns in manufacturing companies, International Journal of Production Economics, 210, 15-26.

Galankashi, M. R., Helmi, S. A. \& Hashemzahi, P. (2016). Supplier selection in automobile industry: a mixed balanced scorecard-fuzzy AHP approach, AEJ - Alexandria Engineering Journal, 55(1), 93-100.

Ghadimi, P., Wang, C., Lim, M. K. \& Heavey, C. (2019). Intelligent sustainable supplier selection using multi-agent technology: theory and application for industry 4.0 supply chains, Computers \& Industrial Engineering, 127, 588-600.

Gou, X.J., Xu, Z. S. \& Liao, H. C. (2017). Hesitant fuzzy linguistic entropy and cross-entropy measures and alternative queuing method for multiple criteria decision making, Information Sciences, 388-389, 225-246.

Gupta, S., Soni, U. \& Kumar, G. (2019). Green supplier selection using multi-criterion decision making under fuzzy environment: a case study in automotive industry, Computers \& Industrial Engineering, 136, 663-680.

Han, J., Wu, X. \& Liu, J. G. (2018). An online sequential procurement mechanism under uncertain demands in multi-cloud environment, International Journal of Approximate Reasoning, 103, 152-167.

Kaviani, M. A., Peykam, A., Khan, S. A., Brahimi, N. \& Niknam, R. (2020). A new weighted fuzzy programming model for supplier selection and order allocation in the food industry, Journal of Modelling in Management, 15(2), 381-406.

Kellner, F. \& Utz, S. (2019). Sustainability in supplier selection and order allocation: Combining integer variables with Markowitz portfolio theory, Journal of Cleaner Production, 214, 462-474.

Khalilzadeh, M., Karami, A. \& Hajikhani, A. (2020). The multi-objective supplier selection problem with fuzzy parameters and solving the order allocation problem with coverage, Journal of Modelling in Management, 15(3),705-725.

Krishankumar, R., Gowtham, Y., Ahmed, I., Ravichandran, K. S. \& Kar, S. (2020). Solving green supplier selection problem using q-rung orthopair fuzzy-based decision framework with unknown weight information, Applied Soft Computing, 94, 106431 .

Manello, A. \& Calabrese, G. (2018). The influence of reputation on supplier selection: an empirical study of the European automotive industry, Journal of Purchasing and Supply Management, 25(1), 69-77.

Mohammadi, M. (2020). Designing an integrated reliable model for stochastic lot-sizing and scheduling problem in hazardous materials supply chain under disruption and demand uncertainty, Journal of Cleaner Production, 274, 122621.

Pamucar, D., Yazdani, M., Obradovic, R., Kumar, A. \& Torres, M. (2020). A novel fuzzy hybrid neutrosophic decision-making approach for the resilient supplier selection problem, International Journal of Intelligent Systems, 35(12), 1934-1986.

Poudel, S. R., Marufuzzaman, M. \& Bian, L. (2016). Designing a reliable bio-fuel supply chain network considering link failure probabilities, Computers \& Industrial Engineering, 91, 85-99.

Salam, M. A. \& Ali, M. (2020). Building reputation through sustainable supplier selection: the case of an emerging economy, European Journal of Management and Business Economics, 29(3), 315-332.

Sarkar, B., Sarkar, M., Ganguly, B. \& CárdenasBarrón, L. E. (2020). Combined effects of carbon emission and production quality improvement for fixed lifetime products in a sustainable supply chain management, International Journal of Production Economics, 231, 107867.

Setiawan, A., Silitonga, R., Angela, D. \& Sitepu, H. I. (2020). The Sensor Network for Multi-agent System Approach in Smart Factory of Industry 4.0, International Journal of Automotive and Mechanical Engineering, 17(4), 8255-8264.

Seyed Haeri, S. A. \& Rezaei, J. (2019). A greybased green supplier selection model for uncertain environments, Journal of Cleaner Production, 221, 768-784

Sillanp, V., Liesi, J. \& Kki, A. (2021). Procurement decisions over multiple periods under piecewiselinear shortage costs and fixed capacity commitments, Omega, 100, 102207.

Tang, S. Y., Gurnani, H. \& Gupta, D. (2014). Managing disruptions in decentralized supply chains with endogenous supply process reliability, Production \& Operations Management, 23(7), 1198-1211.

Tirkolaee, E. B., Mardani, A., Dashtian, Z., Soltani, M. \& Weber, G. W. (2020). A novel hybrid method using fuzzy decision making and multi-objective programming for sustainable-reliable supplier selection in two-echelon supply chain design, Journal of Cleaner Production, 250(20), 119517. 
Xu, Z. S. (2002). On method for multi-objective with partial weight information, Systems Engineeringtheory \& Practice, 22(1), 43-47.

Xu, Z. S. (2007). Multiple-attribute group decision making with different formats of preference information on attributes, IEEE Transactions on Systems, Man, and Cybernetics, Part B: Cybernetics, 37(6), 1500-1511.

Xu, Z. S. \& Wang, H. (2016). On the syntax and semantics of virtual linguistic terms for information fusion in decision making, Information Fusion, 34, 43-48.

Yaghin, R. G. \& Darvishi, F. (2020). Order allocation and procurement transport planning in apparel supply chain: a utility-based possibilistic-flexible programming approach, Fuzzy Sets and Systems, 398, $1-33$.

Yu, M. C. \& Goh, M. (2014). A multi-objective approach to supply chain visibility and risk, European Journal of Operational Research, 233, 125-130.
Yu, M. C., Goh, M. \& Lin, H. C. (2012). Fuzzy multiobjective vendor selection under lean procurement, European Journal of Operational Research, 219, 305-311.

Zhou, F., Wang X., Goh, M., Zhou, L. \& He, Y. (2019). Supplier portfolio of key outsourcing parts selection using a two-stage decision making framework for Chinese domestic auto-maker, Computers and Industrial Engineering, 128, 559-575.

Zhou, X., van Gelder, P. H. A. J. M., Liang, Y. \& Zhang, H. (2020). An integrated methodology for the supply reliability analysis of multi-product pipeline systems under pumps failure, Reliability Engineering and System Safety, 204, 107185.

Zimmermann, H. J. (1978). Fuzzy programming and linear programming with several objective functions, Fuzzy Sets \& Systems, 1(1), 45-55. 